\title{
Compassion and Integrity in Health Professions Education
}

\author{
Randy D. Danielsen \\ Arizona School of Health Sciences, rdanielsen@atsu.edu \\ James F. Cawley \\ The George Washington University, purljfc@aol.com
}

Follow this and additional works at: https://nsuworks.nova.edu/ijahsp

Part of the Medicine and Health Sciences Commons

\section{Recommended Citation}

Danielsen RD, Cawley JF. Compassion and Integrity in Health Professions Education. The Internet Journal of Allied Health Sciences and Practice. 2007 Apr 01;5(2), Article 6.

This Manuscript is brought to you for free and open access by the College of Health Care Sciences at NSUWorks. It has been accepted for inclusion in Internet Journal of Allied Health Sciences and Practice by an authorized editor of NSUWorks. For more information, please contact nsuworks@nova.edu. 


\title{
Compassion and Integrity in Health Professions Education
}

\begin{abstract}
Issues related to professionalism have come to the fore in health professions education. Strategies designed to evaluate and increase components of professionalism are now of interest to educators. Skills in improving levels of professionalism can be accurately assessed and taught. Professionalism encompasses attributes of compassion and integrity. Tools to measure indices of compassion have been developed. There are three critical stages in which attributes of compassion and integrity can be assessed: prior to admission, during education, and graduation standards. One effective means of transferring skills related to professionalism is modeling. Health professions educators need to be more aware of the issues related to the assessment of elements of professionalism.
\end{abstract}

\section{Author Bio(s)}

Dr. Randy Danielsen is Dean and Professor at the Arizona School of Health Sciences.

Mr. James Cawley is a professor and director of the PA/MPH Program at The George Washington University.

\section{Acknowledgements}

The authors express their appreciation to: Suzanne Brown, Albert F. Simon, Eric Sauers, Bernadette Mineo, Curt Bay, Tabitha Parent-Buck, Michael Goodwin, Wendy Stierwalt, and David Wayne. 


\title{
IDJAHSP \\ The Internet Jourffal of Allied Health Sciences and Practice http://ijahsp.nova.edu
}

A Peer Reviewed Publication of the College of Allied Health \& Nursing at Nova Southeastern University Dedicated to allied health professional practice and education

http://ijahsp.nova.edu Vol. 5 No. 2 ISSN 1540-580X

Compassion and Integrity in Health Professions Education

\section{Randy D. Danielsen, PhD, PA-C ${ }^{1}$ James F. Cawley, MPH, PA-C ${ }^{2}$}

1. Dean and Professor, Arizona School of Health Sciences, Mesa, Arizona.

2. Professor and Director, PA/MPH Program, School of Public Health and Health Sciences, The George Washington University

United States

Citation:

Danielsen R., Cawley J. Compassion and Integrity in Health Professions Education. The Internet Journal of Allied Health Sciences and Practice. April 2007, Volume 5 Number 2.

\begin{abstract}
Issues related to professionalism have come to the fore in health professions education. Strategies designed to evaluate and increase components of professionalism are now of interest to educators. Skills in improving levels of professionalism can be accurately assessed and taught. Professionalism encompasses attributes of compassion and integrity. Tools to measure indices of compassion have been developed. There are three critical stages in which attributes of compassion and integrity can be assessed: prior to admission, during education, and graduation standards. One effective means of transferring skills related to professionalism is modeling. Health professions educators need to be more aware of the issues related to the assessment of elements of professionalism.
\end{abstract}

\begin{abstract}
Introduction
Issues related to the acquisition and evaluation of professionalism have become prominent in health professions education in recent times. ${ }^{1-10}$ It has been noted that "from the early 1900s to the present, more than a score of reports from foundations, educational bodies, and professional task forces have criticized medical education for emphasizing scientific knowledge over biologic understanding, clinical reasoning, practical skill, and the development of character, compassion, and integrity"11. The transmission of values that enhance professional behavior is an area of medical education that has long been of concern to medical educators, a domain that in spite of its perceived importance has until recently not been actively taught or reliably assessed. ${ }^{12}$ The topic of professionalism in the health professions is a broad one that has been addressed in depth by prominent others.3,7,8,10 In this paper, we select and address two issues related to professionalism in health professions education: compassion and integrity.
\end{abstract}

\section{Can Professionalism Be Taught?}

Since professionalism seems to be closely tied to an individual's personality, what evidence shows that professionalism can be changed? Beckman and Phelan agree that with targeted, defined interventions, it is possible to change specific professional attitudes and beliefs, reasoning, and behaviors. Professional behavior is assessed within the dimensions of relationship and habits of the mind categories developed by Epstein \& Hundert (see Table 1). ${ }^{13,14}$

The importance of an educator's responsibility to insure the development of professionalism is illustrated in the outcomes of unprofessional behaviors while in training. A recent report describes a study of 235 graduates of three allopathic medical schools (Michigan, UCSF, Jefferson) who were disciplined by one of 40 state medical boards between 1990 and 2003 found an association between inappropriate behaviors in medical school and subsequent disciplinary actions by medical regulatory boards $(\mathrm{OR}=3.1, \mathrm{Cl}, 1.9-4.8)$. Medical boards identified a total of 740 violations among those medical graduates tracked; the most frequent categories were drug abuse (15\%) and "unprofessional behaviors" (11\%). The student behaviors that had the highest degree of correlation with downstream risk were "severe irresponsibility" (OR = 8.5), and "severely diminished capacity for self improvement" (OR $=3.1)$. There was a less strong association between MCAT scores and poor 
grades with subsequent risk of disciplinary actions. The conclusions reached were that disciplinary action by a medical board was strongly associated with prior unprofessional behavior in medical school and that "professionalism should have a central role in medical academics and throughout one's medical career."15 Thus, if medical disciplinary infractions are to be reduced, professionalism must be imbued and assessed beginning in the early stages of the health professions educational process.

\begin{tabular}{|c|c|}
\hline Dimension & Examples \\
\hline Cognitive & $\begin{array}{ll}\text { - } & \text { Core knowledge } \\
\text { - } & \text { Basic communication skills } \\
\text { - } & \text { Information management } \\
\text { - } & \text { Applying knowledge to real-world solutions } \\
\text { - } & \text { Using tacit knowledge and personal experience } \\
\text { - } & \text { Abstract problem-solving } \\
\text { - } & \text { Self-directed acquisition of new knowledge } \\
\text { - } & \text { Recognizing gaps in knowledge } \\
\text { - } & \text { Generating questions } \\
\text { - } & \text { Using resources (e.g., published evidence, colleagues) Learning from experience. }\end{array}$ \\
\hline Technical & $\begin{array}{ll}\text { - } & \text { Physical examination skills } \\
\text { - } & \text { Surgical/Procedure skills }\end{array}$ \\
\hline Integrative & $\begin{array}{l}\text { - } \quad \text { Incorporating scientific, clinical, and humanistic judgment } \\
\text { - } \quad \text { Using clinical reasoning strategies appropriately (hypothetico-deductive, pattern } \\
\text { recognition, elaborated knowledge) } \\
\text { - } \quad \text { Linking basic and clinical knowledge across disciplines, managing uncertainty. }\end{array}$ \\
\hline Context & $\begin{array}{ll}\text { - } & \text { Clinical setting } \\
\text { - } & \text { Use of time } \\
\end{array}$ \\
\hline Relationship & $\begin{array}{ll}\text { - } & \text { Communication skills } \\
\text { - } & \text { Handling conflict } \\
\text { - } & \text { Teamwork } \\
\text { - } & \text { Teaching others (e.g., patients, students, and colleagues) } \\
\end{array}$ \\
\hline $\begin{array}{l}\text { Affective/ } \\
\text { Moral }\end{array}$ & $\begin{array}{ll}\text { - } & \text { Tolerance of ambiguity and anxiety } \\
\text { - } & \text { Emotional intelligence } \\
\text { - } & \text { Respect for patients } \\
\text { - } & \text { Responsiveness to patients and society } \\
\text { - } & \text { Caring. }\end{array}$ \\
\hline Habits of Mind & $\begin{array}{ll}\text { - } & \text { Observations of one's own thinking } \\
\text { - } & \text { Emotions } \\
\text { - } & \text { Techniques } \\
\text { - } & \text { Attentiveness } \\
\text { - } & \text { Critical curiosity } \\
\text { - } & \text { Recognition of and response to cognitive and emotional biases } \\
\end{array}$ \\
\hline
\end{tabular}

Source: Epstein,R.M., Hundert, E.M. (2002). Defining and assessing professional competence. JAMA 287 (2) pp226-235.

\section{What is Professionalism?}

Appropriately, professionalism cannot be evaluated unless it is defined. One definition is that "Professionalism is demonstrated through a foundation of clinical competence, communication skills, and ethical and legal understanding, upon which is built the aspiration to and wise application of the principles of professionalism."16 Unfortunately, to some, "the word professionalism carries with it so many connotations, complexities, and nuances, and is so widely used, that it has virtually lost its meaning."17 What is most important for health professions educators, however, is that any definition must specify behaviors that can be observed and evaluated. A key challenge in measuring medical professionalism has been the absence of an effective tool or set of tools. Our inadequacy to fully measure the attributes of professionalism sends a disquieting message to students and fellow health professionals. We profess both compassion and integrity but do not do enough to ensure its presence or development. ${ }^{18}$ At the core of any medical education is the development of compassion, integrity, and competency. The assessment of the first two within the larger context of medical professionalism is further examined in this paper. 
Although important, we do not discuss the perception of the "deprofessionalism" of medicine or changing student values, i.e., those of so-called Generation X, Generation $\mathrm{Y}$, and the Millennium generation.

\section{Compassion and Integrity}

When it comes to defining compassion and integrity, will we know it when we see it? While there is no shortage of literature on the subjects of integrity and compassion, there is little consistency.

\section{Integrity}

According to the Stanford Encyclopedia of Philosophy:

"Integrity is one of the most important and oft-cited of virtue terms. It is also perhaps the most puzzling. For example, while it is sometimes used virtually synonymously with 'moral,' we also at times distinguish acting morally from acting with integrity. Persons of integrity may in fact act immorally-though they would usually not know they are acting immorally. Thus one may acknowledge a person to have integrity even though that person may hold importantly mistaken moral views". 19

Halfon discusses integrity in terms of moral purpose. He describes integrity as a "person's dedication to the pursuit of a moral life and their intellectual responsibility in seeking to understand the demands of such a life." He goes on to say that persons of integrity;

...embrace a moral point of view that urges them to be conceptually clear, logically consistent, apprised of relevant empirical evidence, and careful about acknowledging as well as weighing relevant moral considerations. Persons of integrity impose these restrictions on themselves since they are concerned, not simply with taking any moral position, but with pursuing a commitment to do what is best. ${ }^{20}$

Table 2 contains selected results of a literature review of definitions/discussions of integrity.

\begin{tabular}{|c|c|c|}
\hline Author & Quotes & Year \\
\hline Henry Cloud, PhD & $\begin{array}{l}\text { Integrity is "Character, ethics, and morals." It may be more than that. Integrity } \\
\text { is the quality of being honest and having strong moral principles. }{ }^{21}\end{array}$ & 2005 \\
\hline S. L. Carter & $\begin{array}{l}\text { The word integrity comes from the Latin root integer and historically has been } \\
\text { understood to carry much the same sense, the sense of wholeness: a person } \\
\text { of integrity, like a whole number, is a whole person, a person somehow } \\
\text { undivided. It seems reasonable to encourage and assess integrity, as it may } \\
\text { be the cornerstone of all the virtues that makes for good character. Integrity } \\
\text { requires three very simple and specific steps: } \\
\text { 1. Discerning what is right and what is wrong, } \\
\text { 2. Acting on what you have discerned, even at personal cost, and } \\
\text { 3. Saying openly that you are acting on your understanding of right } \\
\text { from wrong. }{ }^{22}\end{array}$ & 1996 \\
\hline $\begin{array}{l}\text { Wikipedia, the free } \\
\text { encyclopedia }\end{array}$ & $\begin{array}{l}\text { Many people appear to use the word "integrity" in a vague manner as an } \\
\text { alternative to the perceived political incorrectness of using blatantly moralistic } \\
\text { terms such as "good" or "ethical." In this sense the term often refers to a } \\
\text { refusal to engage in lying, blaming or other behavior generally seeming to } \\
\text { evade accountability. Integrity is holding true to one's values. Said another } \\
\text { way: being one's word; doing what you said you would do (by when)/(how) you } \\
\text { said you would do it. Integrity is knowing what is important to you and living } \\
\text { your actions accordingly. It may take the form of a sense of etiquette that runs } \\
\text { very deep, as in religious or political virtues. }{ }^{23}\end{array}$ & 2006 \\
\hline The Worldview dictionary & $\begin{array}{l}\text { "The quality or state of being of sound moral principle; uprightness, honesty, } \\
\text { sincerity." } 24\end{array}$ & \\
\hline
\end{tabular}

\section{Compassion}

While empathy and compassion are sometimes used interchangeably, it is important to point out the differences. Schatz describes empathy as "an emotion; one person's ability to understand and feel what another person is experiencing or feeling."25 Kalish defines empathy as "the ability to enter into the life of another person, to accurately perceive his current feelings and their meanings." 26 Now contrast that with compassion, particularly if you look at compassion as a behavior motivated by empathy. Empathy is regarded as an essential characteristic in good doctors, but postgraduate training could be doing more to stifle it than to foster it. In a three-year cohort study of 61 internal medicine residents in a US medical school, a decline in residents' empathy during the intern year persisted throughout the residency program. Junior doctors completed the interpersonal reactivity index (IRI) on six occasions in three years, with the first data collected during their internship. Anxiety and depression decreased throughout 
the course of the study to the point where graduating residents were better off in terms of mood than population norms-but their empathy never recovered from the effects of the internship year. ${ }^{27}$

The term compassion is often described as a warm or positive feeling toward the patient. While this is not entirely untrue, a more objective definition is needed if one wants to assess it in an individual. Table 3 contains selected results of a literature review of definitions / discussions of compassion.

Table 3. Definitions of Compassion

\begin{tabular}{|l|l|c|}
\hline \multicolumn{1}{|c|}{ Author } & \multicolumn{1}{|c|}{ Quotes } & Year \\
\hline R. Purtilo & $\begin{array}{l}\text { There are three powerful components of compassion: (1) The character trait or virtue of } \\
\text { sympathetic understanding recognized as a virtue, (2) Willingness to carry out your } \\
\text { professional responsibilities toward the patient, recognized as moral duty, and (3) } \\
\text { Readiness to go beyond the call of duty.28 }\end{array}$ & 2005 \\
\hline $\begin{array}{l}\text { Encyclopedic } \\
\text { Theosophical } \\
\text { Glossary }\end{array}$ & $\begin{array}{l}\text { The word compassion comes from the Latin, passio (suffering) and con (with), which } \\
\text { encourage the desire to treat others with sympathy and understanding. "Sympathetic } \\
\text { understanding; the feeling of one's unity with all that is, resulting in an "intimate magnetic } \\
\text { sympathy with all that is." 29 }\end{array}$ & 2006 \\
\hline $\begin{array}{l}\text { Wordnet @ } \\
\text { Princeton }\end{array}$ & $\begin{array}{l}\text { A deep awareness of and sympathy for another's suffering; the humane quality of } \\
\text { understanding the suffering of others and wanting to do something about it. 30 }\end{array}$ & 2006 \\
\hline Wikipedia & $\begin{array}{l}\text { A sense of shared suffering, most often combined with a desire to alleviate or reduce } \\
\text { such suffering. 31 }\end{array}$ & 2006 \\
\hline $\begin{array}{l}\text { The Free } \\
\text { Dictionary }\end{array}$ & Deep awareness of the suffering of another coupled with the wish to relieve it. 32 & 2006 \\
\hline
\end{tabular}

Why are Compassion \& Integrity so Difficult to Measure?

Current assessment methods for medical and health science students reliably test core knowledge and basic skills. These methods, however, may underemphasize some important domains of professional practice, such as interpersonal skills, lifelong learning, compassion, and integrity. Both compassion and integrity may be difficult to measure because educators do not find or create the opportunities to observe these attributes in either the didactic or clinical components of training. Even if that occurs, it is clear that evaluators usually observe students on their best behaviors and rarely in realistic settings. Educators must find a way to describe the behaviors, which they wish to measure, and then determine if the observations are representative. Skaff, et al provides a list of hypothetical elements of compassion (Figure 1). ${ }^{33}$

\section{Figure 1. Hypothetical Elements of Compassion}

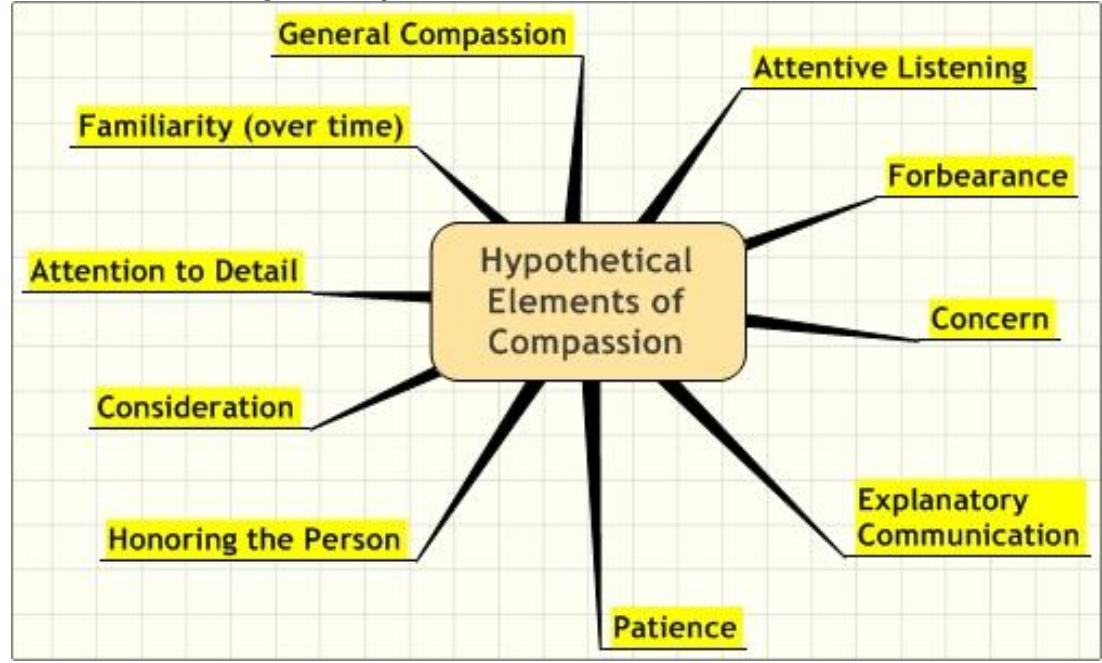

Adapted from Skaff, et al. JAAPA Vol 16. No. 1, January 2003

Tools to Assess/Measure Compassion \& Integrity What are "effective" tools to assess compassion and integrity? One description notes that evaluation (assessment) is the "process of collecting, synthesizing, and interpreting information to aid decision-making." 34 The results of such educational evaluation, according to Millan, "should allow sound inferences about what learners know, believe, and can do in defined contexts." 35 Shostak states that evaluation is a skilled task. Recognizing that "informal" evaluation goes on minute-by-minute, day-by-day, and term-by-term within schools, there is a need to become rigorous in our study of clinical practice. There is a need to develop clear criteria and the skills of focusing on evidence. ${ }^{36}$ The Accreditation Council for Graduate Medical Education (ACGME) has an effective checklist (see Table 4) which 
could be used in evaluating any assessment method. The Accreditation Council for Graduate Medical Education (ACGME) has identified and started requiring certain competencies in medical education. It is anticipated that future licensing requirements at all levels of medical education will require some sort of competency-based assessment, combined with coursework and time-based standards. ${ }^{37}$ Few educators have taken the time to consider substantively and systematically the skills, attitudes, levels of knowledge, and behaviors of competent clinicians, and how these factors may be measured. A statement of competence should incorporate the assessment of skills to specified standards, relevant knowledge and understanding, and the ability to use skills and to apply knowledge and understanding to the performance of relevant tasks. ${ }^{38}$

The concept of competence has evolved over the past 20 years from a one-dimensional model representing specialized knowledge to a more universal one, which includes the "application" of specialized knowledge. It is important to understand that competence does not imply perfection; rather, it implies performance at a stated level. Assessment tools used to measure competence need to be objective, reliable, free of bias, and valid. ${ }^{39}$ Yturri and colleagues state that "to assess competence, one needs to be able to evaluate the knowledge, skills, and abilities represented by behaviors in the actual practice setting. Competence is, therefore, a latent construct, meaning that it is not directly observable in test behavior but must be inferred."40

Measurement has been termed the Achilles heel of socio-behavioral research. Since professional competence is complex and multifaceted, it is difficult to adequately measure this attribute in a simple and inexpensive manner. Since competence is multidimensional, its assessment should also be multidimensional with a performance-based component. The Educational Council of the American Academy of Physician Assistants has identified four properties or dimensions of competence where "each dimension is a continuum and an individual assessment task or method can be high on some dimensions and low on others. In choosing an assessment method, it is important to select one that matches the preferences of the profession along each dimension." 41 The 4 dimensions are depicted in Figure 2.

Figure 2. Four Properties or Dimensions of Assessment of Competence

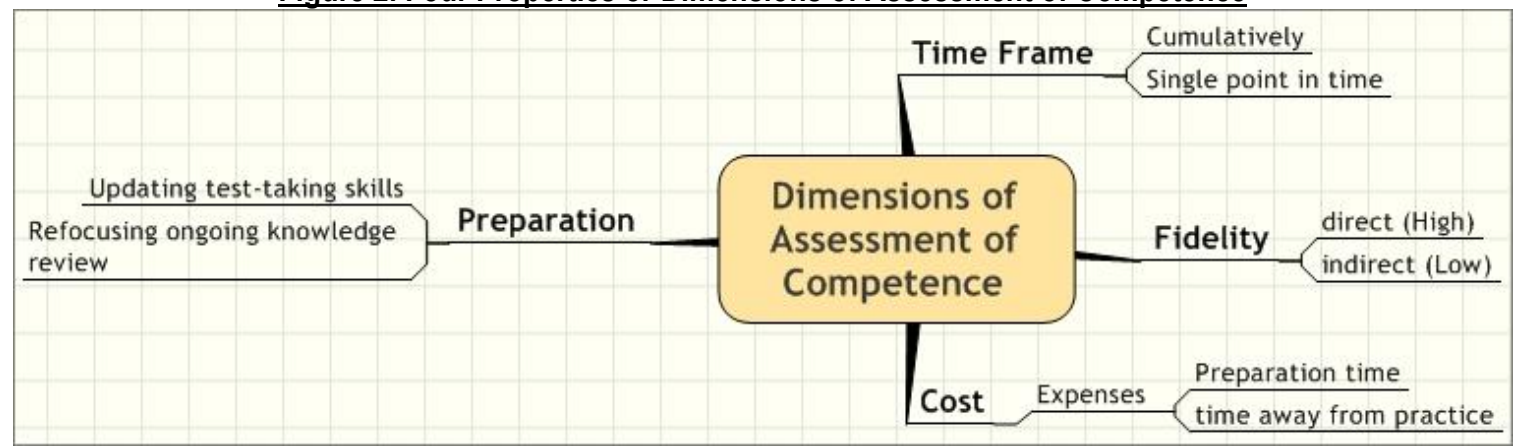

Adapted from: Yturri, K., DeVanzo, J.E., Asprey, D.P., et al. Maintaining your professional competence. JAAPA. 1998:11(8).25-32.

Table 4. Effective Assessment Checklist

\begin{tabular}{|l|l|}
\hline 1 & Assessment should provide valid data \\
\hline 2 & The assessment approach should yield reliable data \\
\hline 3 & The assessment approach should be feasible \\
\hline 4 & The assessment approach should apply to assessment circumstances (external validity) \\
\hline 5 & The assessment should provide valuable information \\
\hline 6 & The assessment should be consistent with curriculum/program objectives \\
\hline 7 & The educational objectives should be representative of the educational domains of interest \\
\hline 8 & Multiple assessment approaches/instruments should be employed \\
\hline 9 & Multiple observations should be conducted \\
\hline 10 & Multiple observers/raters should provide assessments \\
\hline 11 & Performance should be assessed according to pre-specified standards of criteria \\
\hline 12 & Assessment need to be fair \\
\hline
\end{tabular}

Adapted from "Implementing the ACGME General Competencies Requirements" at Albert Einstein College of Medicine, Committee on Graduate Medical Education. P.14

Each of the dimensions should be considered in choosing a method of assessment. Ultimately, the best assessment of competence would be different for each practitioner based on past experience, entry into the 
profession, type of practice, and style of practice. One promising instrument attempts to measure Emotional Intelligence (EI) which is defined as "a cross-section of emotional and social competencies that determine how well we understand and express ourselves, relate with others, and cope with daily demands and pressures." This instrument measures 15 different factors, any of which can be increased if an individual commits to expanding his or her capabilities. This is significantly different from $I Q$ or personality traits, which are considered to be fixed for life. A growing body of research suggests that emotional intelligence is a better predictor of "success" than the more traditional measures of cognitive intelligence (IQ). The Baron instrument consists of 133 items and takes approximately 30 minutes to complete. It gives an overall $E Q$ score as well as scores for the 5 composite scales and 15 subscales. ${ }^{42}$

Another emotional competence inventory (ECl) tool, based on the seminal work of Boyatzis and Goleman, is a 360-degree assessment and development tool. According to Goleman "The $\mathrm{ECl}$ is the only instrument that incorporates the full depth of my research and that of my colleagues. Other instruments use the words 'emotional intelligence' but the $\mathrm{ECl}$ is the genuine article."43

\section{How and When Should We Measure Compassion \& Integrity?}

The question is how best to define, assess, and promote compassion and integrity? It is clear that an effective method must be multi-faceted. The success of any health professional is based in part on the professional and interpersonal skills they have developed prior to their professional education, during the process, and in the years post graduation. The methods influencing the professional development of health science students include (1) student selection, (2) the educational process, and (3) standards for graduation.

\section{Student Selection}

Partly as a result of the difficulty of assessment in this area, selection of students is receiving greater attention in the pursuit of globally competent graduates. However, selection processes may be overrated for this purpose. It is certainly difficult to judge an applicant's professionalism based on current screening and interview processes. A review of student selection literature indicates that the competent and ethical practice of medicine requires clinicians and others to possess a range of personal qualities in addition to cognitive ability. Perhaps participation in a problem solving group exercise during the interview day would assist in the evaluation. Also, a reflective paper written longhand during the interview day based on a scenario can be helpful. ${ }^{44}$

Admission to medical school is based largely on academic achievement, which is influenced by gender, educational background, and social class, but psychometric tests have been used for some years in the United States and Australia, usually for assessing applicants' cognitive ability. A three-part battery of psychometric tests, called the personal qualities assessment (PQA) seems to be reliable in assessing medical school applicants' personality traits and ethical and moral reasoning, as well as their cognitive ability. 45 PQA was tested in medical schools in the United Kingdom, Australia, Israel, and Fiji. Cognitive ability did not vary in relation to gender or educational background, though it tended to be lower in applicants from more deprived backgrounds. Women as a group were more empathetic. Also, applicants from independent and state funded schools had similar psychometric scores. Morrison concluded that an admissions process based on the PQA instrument would not disadvantage applicants from deprived backgrounds. ${ }^{46}$ Regardless of how successful we are in this selection, it would still be necessary to educate in the areas of professionalism during the educational process.

\section{Educating Professionals}

An important aspect of any professional educational curriculum is the development of professional behaviors and role identity. Evidence, as noted earlier, shows that unprofessional behavior exhibited during the educational process is a predictor of future problems with regulatory boards and the need for disciplinary action. Both subjective and objective measures should occur during the educational process to assess professionalism. Figures $3 \& 4$ suggest templates for creating a plan for assessments in both the didactic and clinical years of education. 
Figure 3. Assessing Professionalism in the Didactic Curriculum

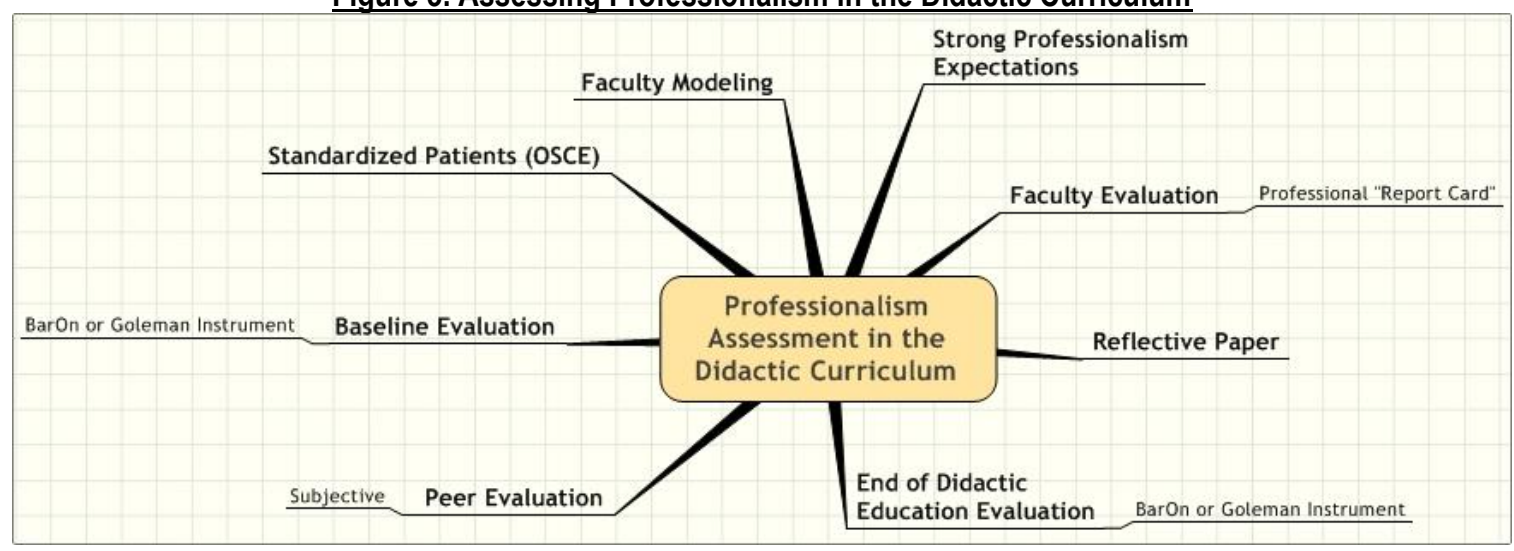

Figure 4. Assessing Professionalism in the Clinical Year(s)

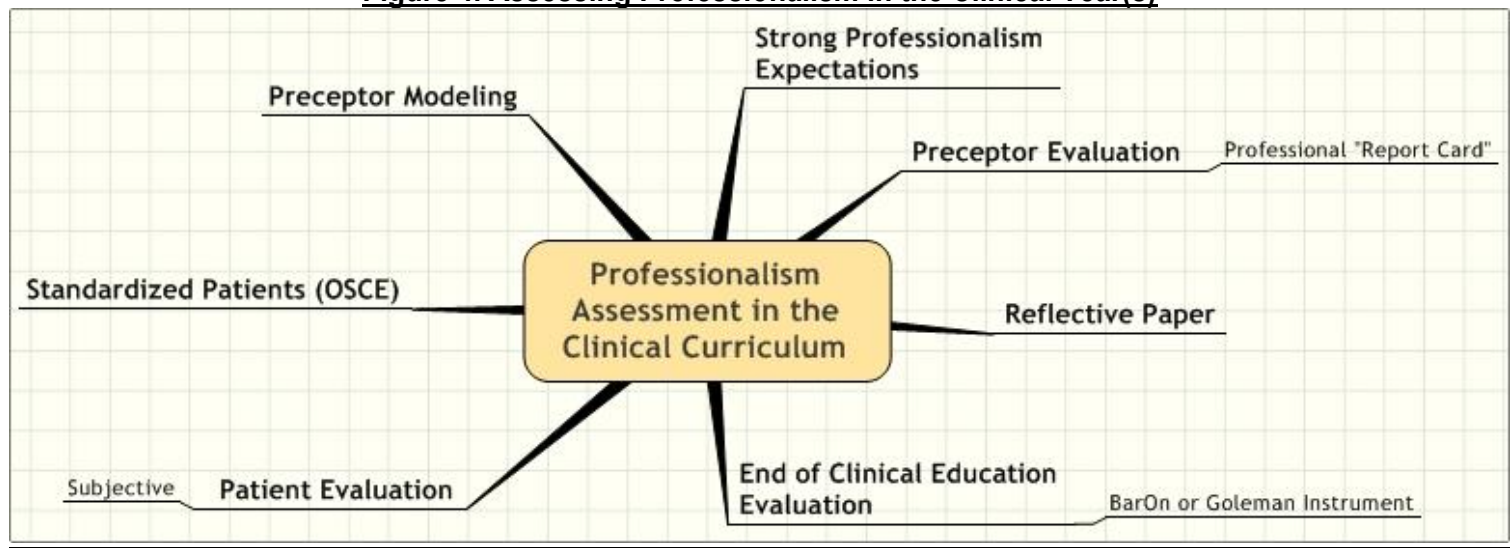

The most objective assessment tools noted above are the Baron and Goleman instruments. Recent literature suggests that emotional intelligence is important in determining leadership success, including professional behavior. Bachrach notes that:

Cognitive intelligence (represented as a normal score usually referred to as ' $Q Q$ ', or intelligence quotient) is, in all probability, 'hard-wired' at birth. Knowledge is gained through study and experience throughout life. Both IQ (inherent intelligence) and acquired knowledge are essential for entry into the field of medicine, and promotion and success in the academic ranks of the health and biomedical sciences. ${ }^{47}$

Bacharach suggests that high intelligence alone does not correlate to success as a leader. With more than 30 years of experience in academic medicine, Bacharach stated "The well-functioning, successful, and emotionally healthy individual is one who possesses a sufficient degree of emotional intelligence." Emotional intelligence (El) has been defined as "the ability to monitor one's own and others' feelings and emotions, to discriminate between them, and to use the information to guide one's thinking and actions."48 Emotional intelligence, as a collective emotional domain, may have relevance to health professions education because professionals have to work in team settings. According to Rowley,

These are extremely powerful tests. It is imperative ethically and behaviorally that after administration that the results be reviewed with the subjects. This can be done in a large group when there are no difficulties. However, if there are any subjects that have scores even one scale that is below what is expected, then there must be a one-on-one interview with someone qualified to discuss the results with the subject and frame them as a challenge and how change can occur for this individual. In other words, the EQi test is a catalyst for change and results, if not handled correctly, can alienate the subject and further entrench the very behavior that needs to be changed. 49

It is also important to note that these instruments require a "certified" person to interpret them. The cost of such measurements is relatively expensive. Assessing actual attitudes and behavior during the course is arguably a better way of ensuring that medical graduates are competent in these areas. Judgments about attitudinal and behavioral competence are legitimate, and need be no more arbitrary than those made about scientific or clinical knowledge and skills, but also that these judgments should be restricted to what is agreed to be unacceptable behavior, rather than attempting to rate attitudes and behavior positively. This suggests that teachers and mentors must demand appropriate behaviors when they interact with students in clinical teaching encounters. Yet the dynamics of that encounter places demands on teachers as well as students. 
At times, teachers may not fill the role of demanding professional behavior in students. A 1999 study of medical resident teams in academic health centers used a "multimethod" qualitative, case study approach. Attending physicians identified 3 problem areas among students (a) disrespect for patients, (b) cutting corners, and (c) outright hostility or rudeness (50). Attendings however, did not always correct unprofessional behavior even when it was identified. They tended to use humor or downplay the behavior rather than constructively correct inappropriate professional behavior.

\section{Standards for Graduation \\ According to Punkett:}

"If ethical, professional, and interpersonal skills are important to the profession and should be taught in professional programs, then students need structured feedback on these behaviors, just as they receive feedback on their medical knowledge and clinical skills..... These competencies can be utilized and, in turn, required for graduation, just as other competencies have been." 51

Institutions can begin by publishing standards that address professional behavior in addition to the usual academic and technical standards. Expectations need to be made clear to students and basic information and skills must be taught.

\section{Modeling}

"Cognitive psychology has taught us that facts and concepts are best recalled and put into service when they are taught, practiced, and assessed in the context in which they will be used."52 One cannot overestimate the importance of modeling and the role of supervisors and faculty in the process of fostering compassion and integrity in health care workers. ${ }^{48}$ There is considerable agreement that modeling of professional behaviors including compassion and integrity - by health professions faculty is among the more effective methods to transmit these values to students.

\section{Conclusion}

Health care professionals are expected by society to meet the highest professional and ethical standards. Health professions educators must provide these clinicians of tomorrow with the foundational knowledge base and skills (compassion and integrity in addition to clinical competence) necessary to achieve these expectations. Professional attitudes and behaviors have only recently begun to be explicitly recognized by medical educators as legitimate and necessary components of competence. Medical schools have recently begun to introduce teaching and assessment of professionalism, including attitudes and behaviors and methods and measures of the two key elements of compassion and integrity.

One of the most effective ways of teaching professionalism is for instructors to model appropriate behavior and to impose a consistent policy of zero tolerance for unprofessional behavior. ${ }^{10}$ Modeling is regarded as the best and most practical methods of transferring professional values and attitudes.

In this paper, we have addressed only two - compassion and integrity - of the many facets of medical professionalism. The authors encourage continued healthy discussions focused on appropriate meanings and assessment measures for compassion and integrity. Further discussions on curricula and competencies designed to better transmit these values should assist health professions educators in the development of new benchmarks.

\section{References}

1. Cruess, S., Johnston, S., Cruess, R. "Profession: A Working Definition for Medical Educators." Teaching and Learning in Medicine 2003, 16(1): 74-76.

2. Hilton, S., Slotnick, H. "Proto-Professionalism: how professionalisation occurs across the continuum of medical education." Med Ed 2005, 39: 58-65.

3. Huddle, T. "Teaching Professionalism: Is Medical Morality a Competency." Acad Med 2005, 80(10): 885-891.

4. Kirk, L., Blank, L. "Professional Behavior - A Learner's Permit for Licensure." NEngl J Med 2005, 353(25): $2709-2711$.

5. Leach, D. "Competence Is a Habit." JAMA 2002, 287(2): 243-244.

6. Cruess, R., Cruess, S. "Teaching Professionalism: General Principles." Med Teacher 2006, 28(3): 205-208.

7. Coulehan, J. Today's Professionalism: Engaging the Mind Not the Heart. Academic Medicine 2005;80:892-898.

8. Reynolds, PP. Reaffirming Professionalism Through the Education Community. AnnIntMedicine 1994;120:609-614.

9. Goldstein, EA, Maestas, RR, Fryer-Edwards, K., Wenrich, MD, et.al. Professionalism in Medical Education: An Institutional Challenge Academic Medicine 2006; 81:871-876.

10. Duffy, P. Teaching and Assessing Professionalism in Medicine. Obstetrics \&Gynecology 2004; 104:1362-1366.

11. Cooke, M., Irby, DM, Sullivan, W., Ludmerer, K. American Medical Education 100 Years After the Flexner Report. NewEngJMed 2006; 355:1339-1344.

12. Cohen, R. Assessing professional behavior and medical error. Medical Teacher, 2001;25:XX-XX.

13. Beckman, H. Frankel, R., Kihm, J, Julesza, G, Geheb, M. Measurement and improvement of humanistic skills in firstyear trainees. J Gen Intern Med 1990; 5:42-5 
14. Phelan, S. Obenshain, S, Galey, WR. Evaluation of non-cognitive professional traits of medical students. Acad Med 1996; 8:195-9.

15. Papadakis, MA; Teherani, A; Banach, MA; Knettler, TR; Rattner, SL; Stern, DT, Veloski, JJ; Hodgson, CS. Disciplinary action by medical boards and prior behavior in medical school. NEJM. 2005;353:2673-2682.

16. Stern D.T. Measuring medical professionalism. 2006. Oxford Press. P.31

17. Swick, HM. Toward a normative definition of medical professionalism. Academic Medicine 2000; 75:612-616.

18. Stern D.T. Practicing what we preach? An analysis of the curriculum of values in medical education. Am J Med. 1998; 104:569-575

19. [Online] http://plato.stanford.edu/entries/integrity/ accessed on 7/17/06

20. Halfon, Mark (1989). Integrity: A Philosophical Inquiry. Philadelphia: Temple University Press, p. 37.

21. Cloud, H. Integrity: the courage to meet the demands of reality. 2006. Collins. P.31.

22. Carter, S.L. Integrity. 1996. Harper Perennial. P7.

23. [Online] http://en.wikipedia.org/wiki/Integrity, accessed on 7/17/06

24. [Online] http://www.summit.org/resource/dictionaryl, Accessed on 7/17/06

25. Schatz, I.J. Empathy and medical education. Hawaii Med J. 1995; 54:495-497.

26. Kalisch, B.J. What is empathy? Am J Nurs. 1973; 73:1548-1552.

27. Medical Education 2005; 39: 258-65

28. Purtilo, R. Ethical dimensions in the health professions, $4^{\text {th }}$ edition. 2005. Elsevier Saunders. P. 267.

29. [Online] http://www.theosociety.org/pasadena/etgloss/ci-cz.htm, Accessed 7/17/06

30. [Online] wordnet.princeton.edu/perl/webwn, Accessed 7/17/06

31. Wikipedia, the free encyclopedia [Online] en.wikipedia.org/wiki/Compassion

32. The Free Dictionary [Online] [ http://www.thefreedictionary.com/compassion]

33. Skaff, $\mathrm{K}$, et al. JAAPA 2003;6:

34. Airasian PW. Classroom assessment (3rd ed). New York: McGraw Hill, 1997

35. Millan JH. Essential assessment concepts for teachers and administrators. Thousand Oaks, CA: Corwin Press, Inc., 2001]

36. Shostak R. The Role and Practice of Evaluation in Local Government Authorities or Evaluation...So What in Murphy R and Torrance H (1989) Educational Evaluation: Issues and Methods. London, Paul Chapman Printing, 1987.

37. Implementing the ACGME General Competencies Requirements" at Albert Einstein College of Medicine, Committee on Graduate Medical Education. P.14.

38. Ashworth P and Saxton J. On 'Competence' Journal of Further and Higher Education. 1990: 14 (2), 3 -25.

39. Powers, B.A. \& Knapp, T.R. A Dictionary of nursing theory and research. Newbury Park: Sage Publications, 1990.

40. Yturri, K., DeVanzo, J.E., Asprey, D.P., et al. Assessing professional competence within the PA profession-a white paper. Perspectives on Physician Assistant Education. 1998; 9:201-209.

41. Yturri, K., DeVanzo, J.E., Asprey, D.P., et al. Maintaining your professional competence. JAAPA. 1998:11:25-32. [Randy-need to check this reference]-volume should be the same if both papers are 1998

42. [Online] oominfo.com/directory/Baron_Reuven_351616192.htm. BarOn Emotion Quotient Inventory: Technical Manual. Multi Health Systems, Inc. Toronto, ON, Canada, 1997.

43. Emotional Competence Inventory (ECI) Tool [Online] HTTP://WWW.EICOR.COM/ENGLISH/PAGES/ASSESSMENT.HTML. Accessed on 7/22/06

44. Powis, D., Bore, M. Munro, D., Lumsen, MA. Development of the personal qualities assessment as a tool for selecting medical students. Journal of Adult and Continuing Education, Volume 1, Spring 2005, pp 3-14(12)

45. Lumsden, MA., Miles, Bore, M., Millar, K., Jack, R., Powis, D. Assessment of personal qualities in relation to admission to medical school. Medical Education, Volume 39, p 258. March 2005.

46. Morrison, J. How to choose tomorrows doctors. Medical Education 39: 3

47. Bachrack, DJ. Emotional intelligence is important in determiing leadership success. Academic Physician and Scientist. January 2004.

48. Slovey, P. \& Mayer, JD. Emotional intelligence. Imagination, Cognition and Personality. 1990; 9:185-211.

49. Personal Communication, Beverly Rowley, PhD., August 4, 2006.

50. Burack, JH, Irby, DM, Carline, JD, Root, PL, Larson, E. Teaching Compassion and Respect: Attending Physicians' Responses to Problematic Behaviors. JGenlntMedicine 1999; 14:49-55.

51. Punkett, MJ. Professionalism in physician assistant students. Perspectives on Physician Assistant Education, Vol 13. No. 1, Winter/Spring 2002.

52. Cooke, M., Irby, DM, Sullivan, W., Ludmerer, K. American Medical Education 100 Years After the Flexner Report. NewEngJMed 2006;355:1339-1344.

The authors express their appreciation to: Suzanne Brown, Albert F. Simon, Eric Sauers, Bernadette Mineo, Curt Bay, Tabitha Parent-Buck, Michael Goodwin, Wendy Stierwalt, and David Wayne. 